\title{
EDUCAÇÃO AMBIENTAL: DIAGNÓSTICO DOS PROJETOS DESENVOLVIDOS NAS ESCOLAS MUNICIPAIS DE CURITIBA, PR
}

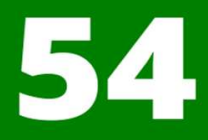

\begin{abstract}
RESUMO
A educação ambiental no ensino formal pode contribuir na mudança de valores e postura em relação a natureza, mudanças sociais e aspectos relacionados a vida dos estudantes como um todo. Projetos de educação ambiental estimulam a interdisciplinaridade e auxilia na sensibilização nos temas ambientais. O objetivo desta pesquisa foi avaliar os projetos de educação ambiental nas escolas municipais de Curitiba, PR. Foram entrevistadas 35 escolas, divididas em escolas municipais com educação integral, com as séries iniciais e finais. Foram aplicados questionários com questões de múltipla escolha sobre os projetos de educação ambiental. Constatou-se que os projetos estão associados ao projeto político pedagógico e as disciplinas do currículo, sendo que a formulação é de iniciativa dos professores e o desenvolvimento conta com os diversos atores da escola. O principal tema abordado foi a água. Conclui-se que os projetos estão alinhados com os conteúdos escolares, além da interação com diversos atores, especialmente os estudantes, que melhoram sensivelmente o interesse nas atividades.
\end{abstract}

Palavras-chave: Meio ambiente. Políticas públicas. Água. 
ENVIRONMENTAL EDUCATION: DIAGNOSIS OF PROJECTS DEVELOPED IN MUNICIPAL SCHOOLS IN CURITIBA, PR

\begin{abstract}
Environmental education in formal education can contribute to changing values and attitude towards nature, social changes and aspects related to the lives of students as a whole. Environmental education projects encourage interdisciplinarity and help raise awareness of environmental issues. The objective of this research was to evaluate environmental education projects in municipal schools in Curitiba, PR. 35 schools were interviewed, divided into municipal schools with integral education, with the initial and final grades. Questionnaires with multiple choice questions about environmental education projects were applied. It was found that the projects are associated with the political pedagogical project and the subjects of the curriculum, with the formulation being the initiative of the teachers and the development relying on the various actors of the school. The main topic addressed was water. It is concluded that the projects are aligned with the school contents, in addition to the interaction with several actors, especially the students, that significantly improve the interest in the activities.
\end{abstract}

Keywords: Environment. Public policies. Water.

Recebido em: 23/09/2021. Aceito em: 13/07/2021. 


\section{INTRODUÇÃO}

A educação ambiental surgiu com as preocupações no aumento populacional e a escassez de recursos naturais em meados da década de 1960, e que aos poucos foi se constatando que muitos dos problemas eram devido ao consumo excessivo de uma parcela pequena da população, dada a concentração de riquezas que acarretava no acúmulo e desperdício de vários produtos (REIGOTA, 2017). Posteriormente foi fortalecida com um viés de proteção e conservação ambiental, mas segundo o mesmo autor, a educação ambiental também está atrelada a aspectos políticos, econômicos, sociais e culturais entre os seres humanos e a natureza, afim de ter uma participação livre (na busca de soluções e alternativas para o bem comum), consciente e democrática.

As primeiras políticas públicas para a promoção da educação ambiental (EA) no Brasil iniciaram a partir de 1995, com enfoque no ensino fundamental (LAMOSA, LOUREIRO; 2011). No final dessa década surgiu a Política Nacional de Educação Ambiental (PNEA) na forma de lei, para orientar as ações a nível nacional.

Na PNEA, a educação ambiental é abordada como uma prática educativa integrada, contínua e permanente, não devendo se constituir disciplina específica no currículo de ensino, exceto nos cursos de pós-graduação, extensão e nas áreas voltadas ao aspecto metodológico da educação ambiental (BRASIL, 2012). Assim, no que concerne o ensino formal no currículo escolar da educação básica (ensino infantil, fundamental e médio), educação superior, educação especial, educação profissional e educação de jovens e adultos, tanto para o ensino público quanto para o privado a educação deve ser desenvolvida como prática contínua, permanente, inter e transdisciplinar (BRASIL, 1999; REIS; SEMÊDO; GOMES, 2016).

Nesse contexto, a escola é um ambiente adequado para repassar diversos conhecimentos, que envolvem valores e postura em relação a natureza, mudanças sociais e aspectos relacionados a vida como um todo (SOUZA; BONOTTO, 2019). De forma interdisciplinar e sistêmica, a escola no ensino formal tem um papel fundamental na formação de cidadãos sensibilizados como meio que estão inseridos e capazes de desenvolver atividades que promovam a sensibilização ambiental (SANTOS et al., 2018).

No ensino fundamental foi averiguado a aplicação da educação ambiental nas escolas através do censo escolar realizado em 2001 e 2003, pelo Instituto Nacional de Estudos e Pesquisas Educacionais Anísio Teixeira (INEP). O censo verificou se as escolas aplicavam 
educação ambiental nas modalidades de projetos, inserção no projeto político pedagógico ou disciplina especial e constatou-se um aumento nas atividades de educação ambiental, principalmente na modalidade projetos (LAMOSA; LOUREIRO, 2011).

Os projetos de educação ambiental possuem alternativas de trabalhar a interdisciplinaridade nas escolas, estimulando a criatividade e o raciocínio dos estudantes a partir de atividades teórico-prático de forma participativa e dinâmica (NARCIZO, 2009).

Considerando a importância da educação ambiental nas práticas de ensino formal, o objetivo desse trabalho foi avaliar como os projetos de educação ambiental são desenvolvidos nas escolas de ensino fundamental da rede pública do município de Curitiba, Paraná.

\section{MATERIAL E MÉTODOS}

A pesquisa foi realizada em Curitiba, capital do estado do Paraná que contempla cerca de 9.029 escolas de educação básica, dos quais, 783 escolas estão localizadas em Curitiba, deste total 484 escolas contemplam o ensino fundamental, mas são apenas 185 escolas disponíveis na rede pública de ensino (SARTORI, 2015; INSTITUTO NACIONAL DE ESTUDOS E PESQUISAS EDUCACIONAIS ANÍSIO TEIXEIRA - INEP, 2017).

As escolas municipais de Curitiba abrangem os anos escolares de 10 a 5 을 e de 10 a 9 응 do Ensino Fundamental, os quais algumas escolas disponibilizam o ensino em tempo integral (contraturno), em que é oferecido um adicional de quatro horas diárias de atividades educativas diferenciada (CURITIBA, 2006).

Para averiguar se havia diferenças na aplicação do tema EA entre nos anos iniciais (1을

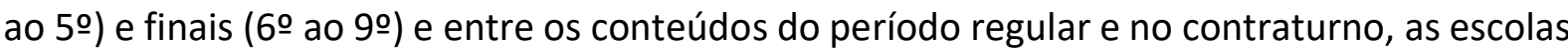
foram divididas em 3 estratos: "Escolas Municipais com as séries iniciais denominado de ciclo 1 (EMCiclo1)", "Escolas Municipais com as séries finais denominado de ciclo 2 (EMCiclo2)" e "Escolas Municipais com educação integral (EMIntegral)". Essa divisão foi feita com base na lista de escolas disponíveis nas Unidades Educacionais (CURITIBA, 2017), a qual considerou como "EMIntegral", as escolas com centro de educação infantil (CEI).

Para efetuar a coleta de dados, a seleção do número de escolas foi calculada através do método de amostragem para uma população finita e desvio padrão desconhecido, considerando como população total o número de escolas municipais em Curitiba (LUCHESA; CHAVES NETO, 2011). 
Foi utilizado uma proporção amostral de sucesso e de fracasso de $50 \%$, tendo em vista que é o percentual recomendado quando a população não é homogênea. A variável aleatória normal padrão utilizada foi de $80 \%$ e o erro amostral foi de $10 \%$ resultando em um $\mathrm{n}$ de no mínimo 34 escolas, como uma das escolas amostradas tinha sede em dois locais diferentes, foi coletado informações das duas escolas resultando em um n de 35 escolas amostradas, distribuídas em 15 escolas para o "EMCiclo1", por abranger um maior número de escolas, 10 escolas para o "EMCiclo2" e 10 escolas para o "EMIntegral".

A seleção das escolas foi realizada randomicamente com base na divisão regional de Curitiba, a partir de um sorteio aleatório seguindo o número de escolas amostradas para cada estrato, distribuídas nas dez regionais do município (FIGURA 1). Caso alguma das escolas selecionadas tivesse algum impedimento para realizar a entrevista, houve substituição por outra escola da mesma regional.

Figura 1: Localização das escolas amostradas

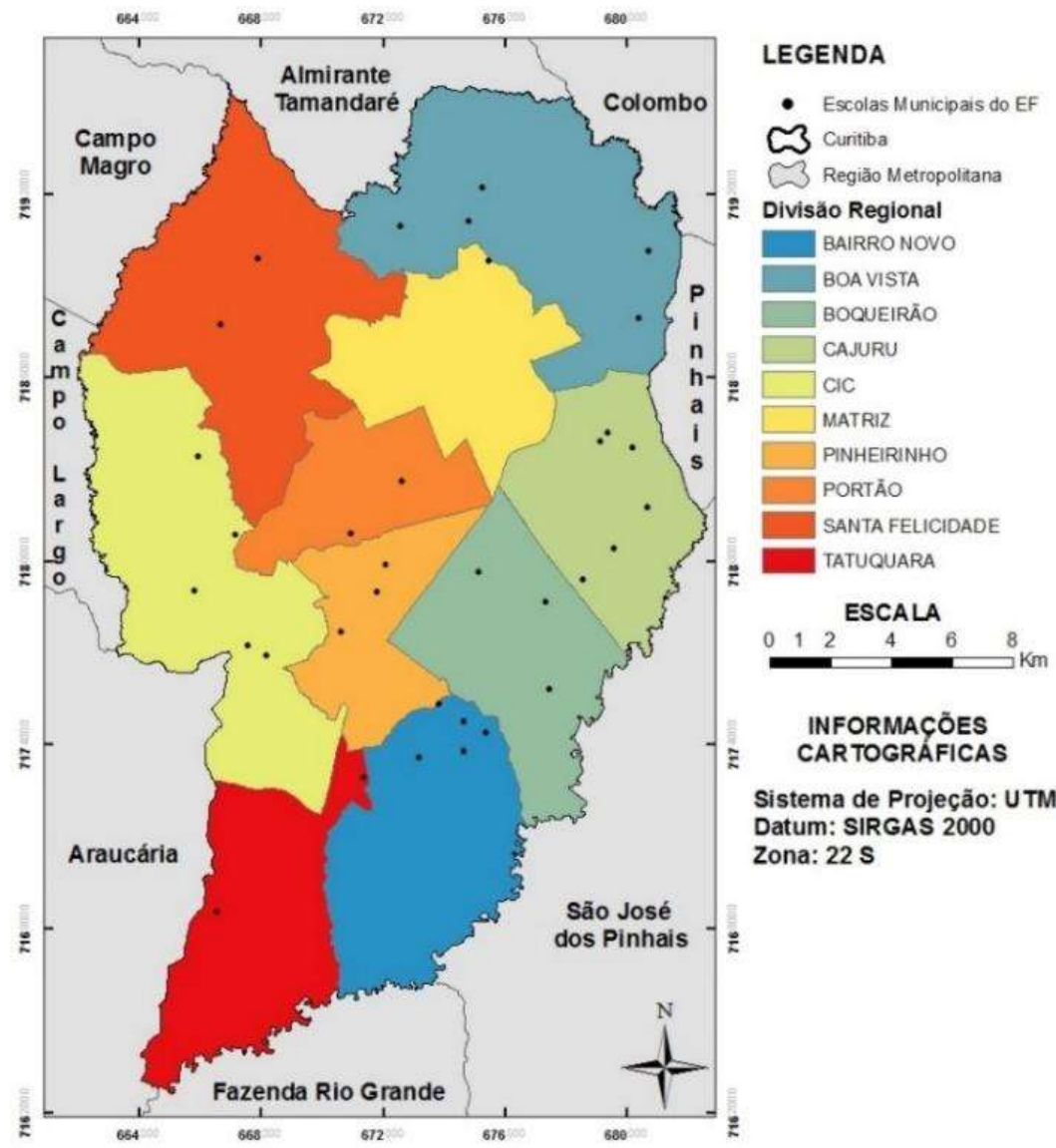

Fonte: Elaborado pelas autoras, 2021. 
A coleta de dados foi iniciada após a aprovação do projeto pela Secretaria Municipal da Educação da Prefeitura Municipal de Curitiba que concedeu uma autorização para a visitação nas escolas.

A coleta dos dados foi referente às atividades de EA formal nas escolas amostradas e foi realizada a partir de entrevistas in loco nas escolas que se dispuseram a auxiliar na pesquisa após contato telefônico, o qual era recomendado que o entrevistado fosse o representante que mais entendia sobre as atividades de EA desenvolvidas na escola, tais como: diretor, vicediretor, articulador pedagógico ou professor. A coleta teve duração de quarenta minutos até uma hora, por meio de um questionário impresso adaptado de Mendonça e Trajber (2007) como uma abordagem quantitativa, composto por perguntas sobre o perfil do entrevistado e referente aos projetos de EA desenvolvidos na escola (FIGURA 2), que foram aplicados no período de agosto de 2016 a abril de 2017.

Figura 2: Questionário aplicado nas escolas

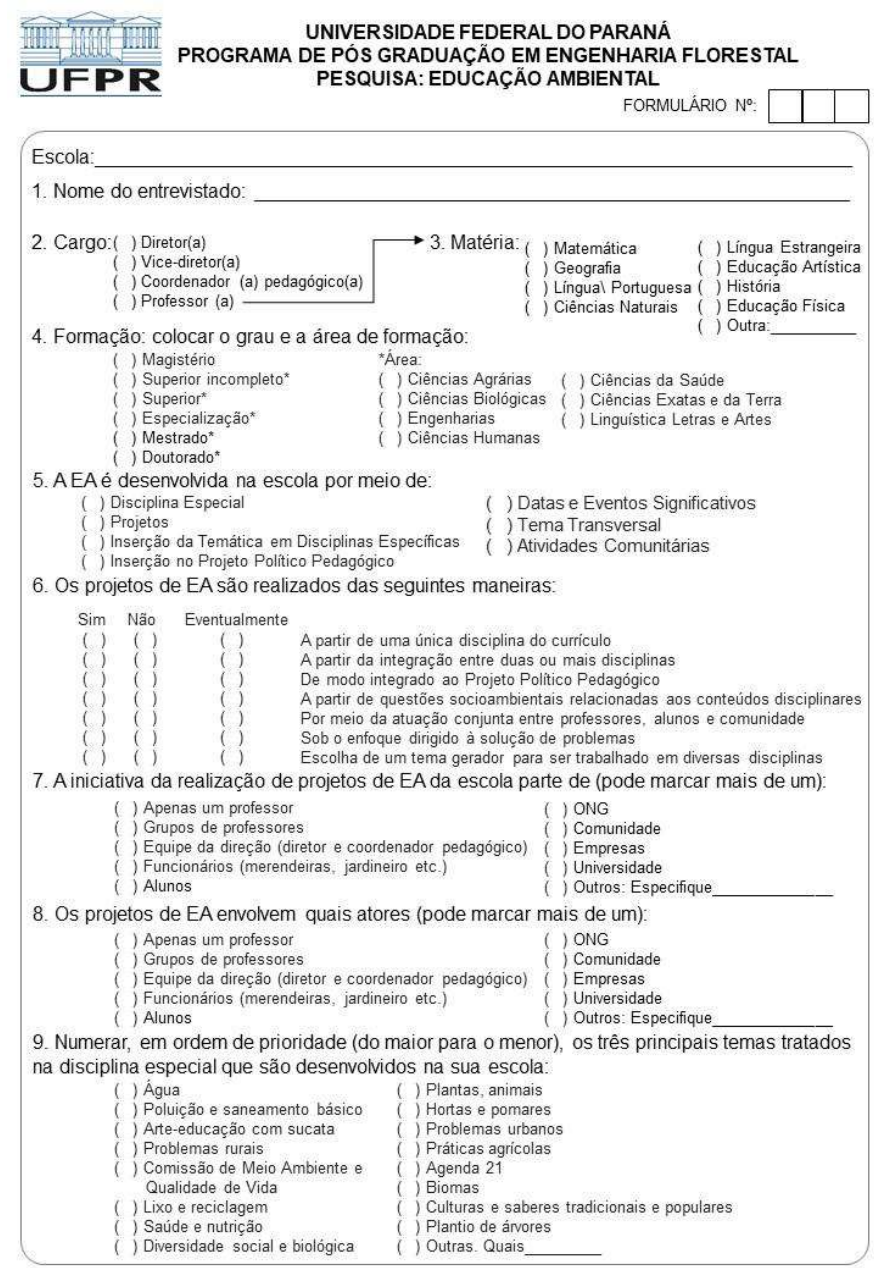

Fonte: Elaborado pelas autoras, 2021 
Após a coleta, os dados foram compilados em planilhas do Excel e foi analisado a descrição das frequências das respostas de cada questão, para a amostra total e por estrato, o qual foi verificado se havia diferença estatística entre os estratos e se as escolas com contraturno tinha alguma vantagem para desenvolver projetos que os demais, para tal foi utilizado a "estatística não paramétrica ou livres de distribuição", ou seja, quando os dados não apresentam uma distribuição normal (SIEGEL; CASTELLAN JR, 2006).

O teste estatístico escolhido para a análise foi o qui-quadrado a 5\% de significância, que compara se dois grupos independentes que diferem em relação a alguma característica, utilizando o software R versão R i386 3.3.1 (SIEGEL; CASTELLAN JR, 2006; R CORE TEAM, 2016).

A análise estatística foi realizada para as perguntas do questionário que mostravam ter uma possível mudança de comportamento entre as escolas, devido à inserção de mais atividades de EA.

\section{RESULTADOS E DISCUSSÃO}

O perfil dos entrevistados das 35 escolas foi na maioria articuladores (as) pedagógicos (as) com $42,9 \%$, seguido de professores com $25,7 \%$ do total.

Os articuladores pedagógicos surgiram em Curitiba com a função de promover diálogo entre os turnos diurno e noturno e aos poucos foram adquirindo diversas funções, tais como: atuação no processo pedagógico da escola, atender os estudantes, auxiliar o professor, realizar conselho de classe, atender o público em geral, entre outros (BRANDT, 2017). Devido as diversas funções demandadas nesse cargo, as escolas consideram esses profissionais mais preparados para responder as questões referentes a educação ambiental.

Os cargos articulador pedagógico, articulador do integral, diretor (a) e vice-diretor (a), não lecionam nenhuma disciplina, participam dos processos de gestão da escola, assim, na distribuição de disciplinas lecionadas, a maior parte dos entrevistados não ministravam disciplina no momento $(71,4 \%)$ seguido da disciplina de ciências naturais $(14,3 \%)$.

Em relação à formação dos entrevistados, $82,9 \%$ são da área de humanas e a maior parte $(77,1 \%)$ tem o nível de especialização, que em geral não está associado a temas que envolvem a EA, assim embora a Política Nacional de Educação Ambiental prevê a capacitação de recursos humanos para preparar profissionais na área de meio ambiente para atender a 
demanda de cada segmento (BRASIL, 1999), não é especificado qual a formação ideal, já que o tema é tratado como transversal aos diversos nichos de conhecimento, portanto uma qualificação específica no assunto não contribui necessariamente para melhor aplicação dos temas relacionados as questões ambientais.

Das 35 escolas entrevistadas, 23 tinham projetos com enfoque em educação ambiental, das quais, quando questionados como os projetos de educação ambiental eram aplicados da escola (TABELA 1), a maior parte integrava o tema ao projeto político pedagógico da escola $(73,9 \%)$ e a partir de questões socioambientais relacionadas aos conteúdos disciplinares $(73,9 \%)$, principalmente para as escolas com turno integral que ocorreu em todas as escolas consultadas. Também é possível perceber que há uma integração entre duas ou mais disciplinas do currículo para a realização dos projetos com um total amostrado de $60,9 \%$, mas ao analisar por tipo de ensino, a EMCiclo2 apresentou baixa interação entre as disciplinas com $28,6 \%$.

Tabela 1: Formas que os projetos de educação ambiental são realizados

\begin{tabular}{|c|c|c|c|c|c|c|c|c|c|c|c|c|}
\hline \multirow{2}{*}{ Opções } & \multicolumn{3}{|c|}{ EMCiclo1 (\%) } & \multicolumn{3}{|c|}{ EMCiclo2 (\%) } & \multicolumn{3}{|c|}{ EMIntegral (\%) } & \multicolumn{3}{|c|}{ Total (\%) } \\
\hline & $\mathbf{E}$ & Não & Sim & $\mathbf{E}$ & Não & Sim & $\mathbf{E}$ & Não & Sim & $\mathbf{E}$ & Não & Sim \\
\hline $\begin{array}{l}\text { A partir de questões } \\
\text { socioambientais relacionadas } \\
\text { aos conteúdos disciplinares }\end{array}$ & 14,3 & 14,3 & 71,4 & 28,6 & 28,6 & 42,9 & 0,0 & 0,0 & 100,0 & 13,0 & 13,0 & 73,9 \\
\hline $\begin{array}{l}\text { De modo integrado ao Projeto } \\
\text { Político Pedagógico }\end{array}$ & 0,0 & 14,3 & 85,7 & 14,3 & 14,3 & 71,4 & 22,2 & 11,1 & 66,7 & 13,0 & 13,0 & 73,9 \\
\hline $\begin{array}{l}\text { A partir da integração entre } \\
\text { duas ou mais disciplinas }\end{array}$ & 28,6 & 14,3 & 57,1 & 28,6 & 42,9 & 28,6 & 0,0 & 11,1 & 88,9 & 17,4 & 21,7 & 60,9 \\
\hline $\begin{array}{l}\text { Sob o enfoque dirigido à } \\
\text { solução de problemas }\end{array}$ & 28,6 & 28,6 & 42,9 & 14,3 & 28,6 & 57,1 & 33,3 & 0,0 & 66,7 & 26,1 & 17,4 & 56,5 \\
\hline $\begin{array}{l}\text { Escolha de um tema gerador } \\
\text { para ser trabalhado em } \\
\text { diversas disciplinas }\end{array}$ & 28,6 & 42,9 & 28,6 & 57,1 & 14,3 & 28,6 & 22,2 & 0,0 & 77,8 & 34,8 & 17,4 & 47,8 \\
\hline $\begin{array}{l}\text { Por meio da atuação conjunta } \\
\text { entre professores, estudantes } \\
\text { e comunidade }\end{array}$ & 28,6 & 28,6 & 42,9 & 42,9 & 28,6 & 28,6 & 33,3 & 11,1 & 55,6 & 34,8 & 21,7 & 43,5 \\
\hline $\begin{array}{l}\text { A partir de uma única disciplina } \\
\text { do currículo }\end{array}$ & 0,0 & 85,7 & 14,3 & 14,3 & 57,1 & 28,6 & 0,0 & 88,9 & 11,1 & 8,7 & 78,3 & 13,0 \\
\hline
\end{tabular}

Ao avaliar estatisticamente a aplicação de projetos nos diferentes tipos de ensino, não houve diferença estatística na forma que os tipos de ensino realizam as atividades de educação ambiental nas escolas, mas embora estatisticamente não tenha aparecido 
diferenças vale ressaltar que nem todas as escolas entrevistadas do EMCiclo1 e EMCiclo2 desenvolveram projetos em seu currículo, já as escolas as escolas que tinham atividades no contraturno (EMIntegral), todas as entrevistadas aplicavam projetos de educação ambiental.

Em comparação com a análise feita no Brasil por Mendonça e Trajber (2007), as escolas também realizam projetos principalmente a partir de questões socioambientais relacionadas aos conteúdos disciplinares (77\%) e estão associados ao projeto político pedagógico (76\%), ao avaliarem a região sul, a pesquisa não contemplou o estado do Paraná, mas comparando com os estados selecionados, Santa Catarina e Rio Grande do Sul, as escolas também realizam projetos integrados ao projeto político pedagógico (60\%) e a partir de questões socioambientais relacionadas aos conteúdos disciplinares (59\%). Por outro lado, esses estados também evidenciaram um aspecto negativo de que muitos projetos partem de uma única disciplina do currículo (59\%), diferentemente da presente pesquisa com uma frequência de $13 \%$ para o município de Curitiba, Paraná. Esses resultados mostram que tanto em âmbito nacional, quanto na região sul, a educação ambiental nas escolas está integrada ao projeto político pedagógico e aos conteúdos disciplinares.

Cruz (2011) afirma a necessidade de incluir ações de educação ambiental desde o início do desenvolvimento da criança, para que possam entender o ambiente onde estão inseridas, observarem o seu funcionamento, sua importância e sua preservação, no qual as escolas podem iniciar esse trabalho associando ao mundo real dos estudantes, ao incluir por exemplo, hábitos, atitudes, comportamentos, sensibilidade, solidariedade, respeito mútuo e a ética na agenda ambiental da escola incluída no projeto político pedagógico.

Analisando a iniciativa para a realização desses projetos, $87,0 \%$ relatam que em geral parte de um grupo de professores, mas também conta com a participação da equipe de direção $(69,6 \%)$, principalmente nas escolas compostas no grupo EMIntegral (100\%) e com menor efetividade no EMCiclo1 com 42,9\%. Também foi possível observar uma baixa relação com a comunidade, empresas ou universidades, as quais auxiliaram apenas uma escola, já as ONGs não incentivaram nenhum projeto das escolas consultadas em Curitiba (TABELA 2). 
Tabela 2: Iniciativa da realização de projetos de educação ambiental

\begin{tabular}{|c|c|c|c|c|c|c|c|c|}
\hline \multirow{2}{*}{ Opções } & \multicolumn{2}{|c|}{ EMCiclo1 } & \multicolumn{2}{|c|}{ EMCiclo2 } & \multicolumn{2}{|c|}{ EMIntegral } & \multicolumn{2}{|c|}{ Total } \\
\hline & $\mathbf{N}$ & $\%$ & $\mathbf{N}$ & $\%$ & $\mathbf{N}$ & $\%$ & $\mathbf{N}$ & $\%$ \\
\hline Grupos de professores & 6 & 85,7 & 6 & 85,7 & 8 & 88,9 & 20 & 87,0 \\
\hline Equipe da direção (diretor e coordenador pedagógico) & 3 & 42,9 & 4 & 57,1 & 9 & 100,0 & 16 & 69,6 \\
\hline Estuantes & 2 & 28,6 & 3 & 42,9 & 6 & 66,7 & 11 & 47,8 \\
\hline Outro & 1 & 14,3 & 3 & 42,9 & 1 & 11,1 & 5 & 21,7 \\
\hline Funcionários (merendeiras, jardineiro etc.) & 1 & 14,3 & 1 & 14,3 & 2 & 22,2 & 4 & 17,4 \\
\hline Apenas um professor & 1 & 14,3 & 0 & 0,0 & 1 & 11,1 & 2 & 8,7 \\
\hline Comunidade & 0 & 0,0 & 1 & 14,3 & 0 & 0,0 & 1 & 4,3 \\
\hline Empresas & 0 & 0,0 & 1 & 14,3 & 0 & 0,0 & 1 & 4,3 \\
\hline Universidade & 1 & 14,3 & 0 & 0,0 & 0 & 0,0 & 1 & 4,3 \\
\hline ONG & 0 & 0,0 & 0 & 0,0 & 0 & 0,0 & 0 & 0,0 \\
\hline
\end{tabular}

LEGENDA: EMCiclo1 = Escolas Municipais com as séries iniciais; EMCiclo2 = Escolas Municipais com as séries finais; EMIntegral = Escolas Municipais com educação integral; N = número de escolas.

Fonte: Elaborado pelas autoras, 2021.

A iniciativa de projetos por agentes fora da comunidade escolar pode ser mais difícil, pois cada escola tem uma realidade e envolvimentos com os temas ambientais de forma diferenciada, sendo os próprios agentes da escola que conhecem as suas eventuais necessidades, mas há casos de campanhas genéricas, como a mobilização contra o Aedes aegypti (FIGURA 3), que são realizados primeiramente por iniciativas externas e que podem ter continuidade em outros projetos ou relacionar com as disciplinas que forem abordar o tema água e insetos.

Figura 3: Palestra sobre a dengue pelo programa de saúde na escola - Curitiba

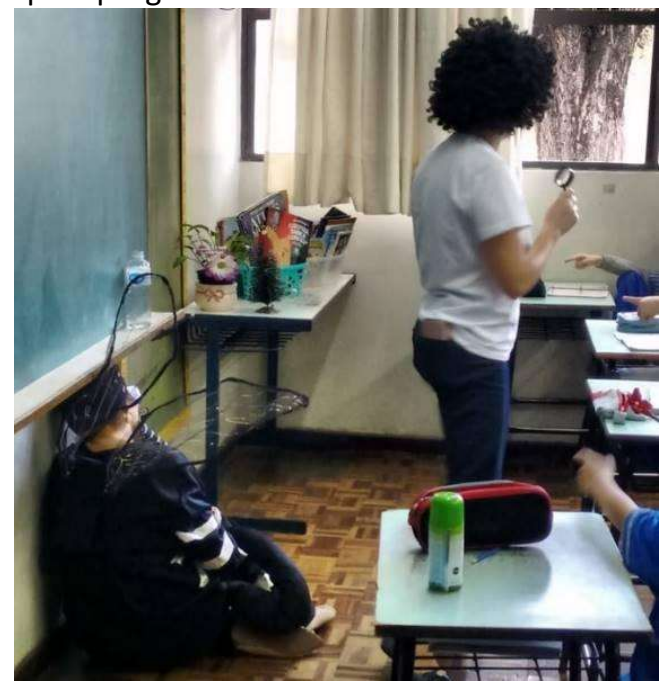

Fonte: Elaborado pelas autoras, 2021. 
Embora o presente trabalho não tenha contemplado iniciativas por parte de ONGs, há trabalhos que identificaram essa parceria na realização de projetos não formais e contam com participação ativa das ONGs por um período, em seguida a responsabilidade da continuidade ficava a cargo da escola (PALMIERI; CAVALARI, 2012). Segundo os mesmos autores, é mais interessante que um agente externo dialogue com a comunidade escolar a respeito de um projeto do que apresentar uma proposta pronta, pois possibilita alinhamento do projeto com as demandas e a necessidade da escola.

Dentre os atores envolvidos para a realização dos projetos nas escolas, 95,7\% são compostos por estudantes e grupos de professores, enquanto $82,6 \%$ das escolas afirmaram que a equipe de direção também auxilia nessa ação, assim como os funcionários (52,2\%), caso seja necessário. Notou-se também uma baixa ação da comunidade em ajudar nas atividades das escolas em todos os tipos de ensino (TABELA 3). As escolas afirmaram que a comunidade do entorno não se preocupa com os projetos desenvolvidos na escola, mas não foi objeto dessa pesquisa avaliar se o entorno teve oportunidade para participar dessas ações e como foi a abordagem por parte da escola.

Tabela 3: Atores envolvidos nos projetos

\begin{tabular}{|c|c|c|c|c|c|c|c|c|}
\hline \multirow{2}{*}{ Opções } & \multicolumn{2}{|c|}{ EMCiclo1 } & \multicolumn{2}{|c|}{ EMCiclo2 } & \multicolumn{2}{|c|}{ EMIntegral } & \multicolumn{2}{|c|}{ Total } \\
\hline & $\mathbf{N}$ & $\%$ & $\mathbf{N}$ & $\%$ & $\mathbf{N}$ & $\%$ & $\mathbf{N}$ & $\%$ \\
\hline Estudantes & 7 & 100,0 & 6 & 85,7 & 9 & 100,0 & 22 & 95,7 \\
\hline Grupos de professores & 7 & 100,0 & 7 & 100,0 & 8 & 88,9 & 22 & 95,7 \\
\hline Equipe da direção (diretor e coordenador pedagógico) & 6 & 85,7 & 6 & 85,7 & 7 & 77,8 & 19 & 82,6 \\
\hline Funcionários (merendeiras, jardineiro etc.) & 2 & 28,6 & 4 & 57,1 & 6 & 66,7 & 12 & 52,2 \\
\hline Comunidade & 2 & 28,6 & 1 & 14,3 & 2 & 22,2 & 5 & 21,7 \\
\hline ONG & 1 & 14,3 & 1 & 14,3 & 0 & 0,0 & 2 & 8,7 \\
\hline Outro & 0 & 0,0 & 1 & 14,3 & 1 & 11,1 & 2 & 8,7 \\
\hline Apenas um professor & 0 & 0,0 & 0 & 0,0 & 1 & 11,1 & 1 & 4,3 \\
\hline Empresas & 0 & 0,0 & 1 & 14,3 & 0 & 0,0 & 1 & 4,3 \\
\hline Universidade & 1 & 14,3 & 0 & 0,0 & 0 & 0,0 & 1 & 4,3 \\
\hline
\end{tabular}

Para Palmieri e Cavalari (2013), ao incorporar os estudantes nos projetos de educação ambiental no ensino formal é possível trabalhar com a realidade local, inserir novos conhecimentos e promover mudança de valores, atitudes e comportamentos. Há pesquisas 
que reforçam a participação dos estudantes no processo educativo para haver um maior interesse nos projetos realizados na escola. O envolvimento de diversas partes, tais como os professores, na integração das diversas disciplinas nos projetos, pais dos estudantes, toda comunidade escolar e do entorno, melhoram o modelo tradicional de ensino e abrem portas para novas concepções e práticas de educação ambiental (PALMIERI; CAVALARI, 2012).

Para Narcizo (2009), não basta fazer projetos impostos por um grupo isolado ou por um professor, com atividades que não proporcione mudança na mentalidade dos estudantes, o trabalho tem que ser de forma integrada, com mais agentes da comunidade escolar e com alternativas que promovam uma contínua reflexão, possivelmente conseguirá implantar um projeto de educação ambiental fidedigno.

Em relação aos principais temas abordados nos projetos, foi pedido que as escolas listassem os três principais e o primeiro tema a ser tratado foi "água" com 34,8\%, o segundo foi "lixo e reciclagem" com $26,1 \%$ e o terceiro foi "saúde e nutrição" com $26,1 \%$. Um dos exemplos desse último tema foi o projeto prato limpo (FIGURA 4), realizado por uma escola que avalia o desperdício de comida de cada turma e aquela que tiver menor desperdício fazia um piquenique no parque.

Figura 4: Projeto prato limpo - Curitiba

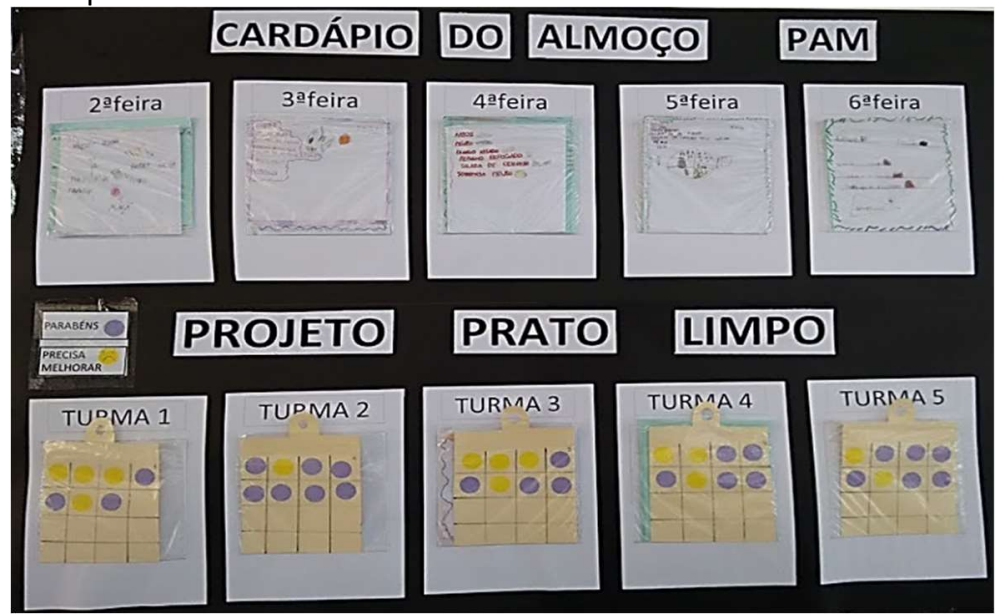

Fonte: Elaborado pelas autoras, 2021

Na avaliação feita a nível nacional, o tema principal avaliado nos projetos também foi a água $(98,1 \%)$ seguido de lixo e reciclagem com $62,8 \%$. Assim, para o estado de Santa Catarina e Rio Grande do Sul, esses temas também foram os principais, seguido de saúde e nutrição (MENDONÇA; TRAJBER, 2007).

A água como principal tema nos projetos de educação ambiental, tanto para o presente estudo como em outros estados, pode estar atrelado ao fato de ser um assunto 
constantemente em discussão pelos cidadãos em diversos segmentos sociais, mídias, legislações e está pautada em livros didáticos e em propostas pedagógicas, cabendo a escola contribuir para um pensamento global a respeito da crise hídrica e práticas voltadas a novos hábitos e atitudes no uso racional da água (FREITAS, MARIN; 2015).

Um exemplo de novos hábitos foi descrito por Higuchi, Zattoni e Bueno (2012), em que uma escola passou a reutilizar a água de bebedouros que antes eram desperdiçadas e começaram a armazenar em caixas d'água para posterior uso em descargas de vasos sanitários e lavagem do pátio da escola, projeto que só foi possível com a participação de todos os atores da comunidade escolar.

Narcizo (2009) também acredita que a participação dos atores, principalmente os estudantes, é muito importante, pois por exemplo, em um projeto de resíduos sólidos, não basta que os estudantes separem os resíduos nas lixeiras corretas e sim ações que proporcione uma mudança de comportamento em reduzir o consumo, reutilizar e reciclar os resíduos, para essas atitudes se estendem em todo o ambiente escolar e em outros locais fora da escola.

Outro projeto que foi frequente nas escolas consultadas foi o projeto de "horta e pomares" (FIGURA 5), que embora não esteja entre os três temas principais abordados nas escolas, está associado a outros assuntos, tais como a água, saúde e nutrição.

Figura 5: Atividade de horta nas escolas - Curitiba
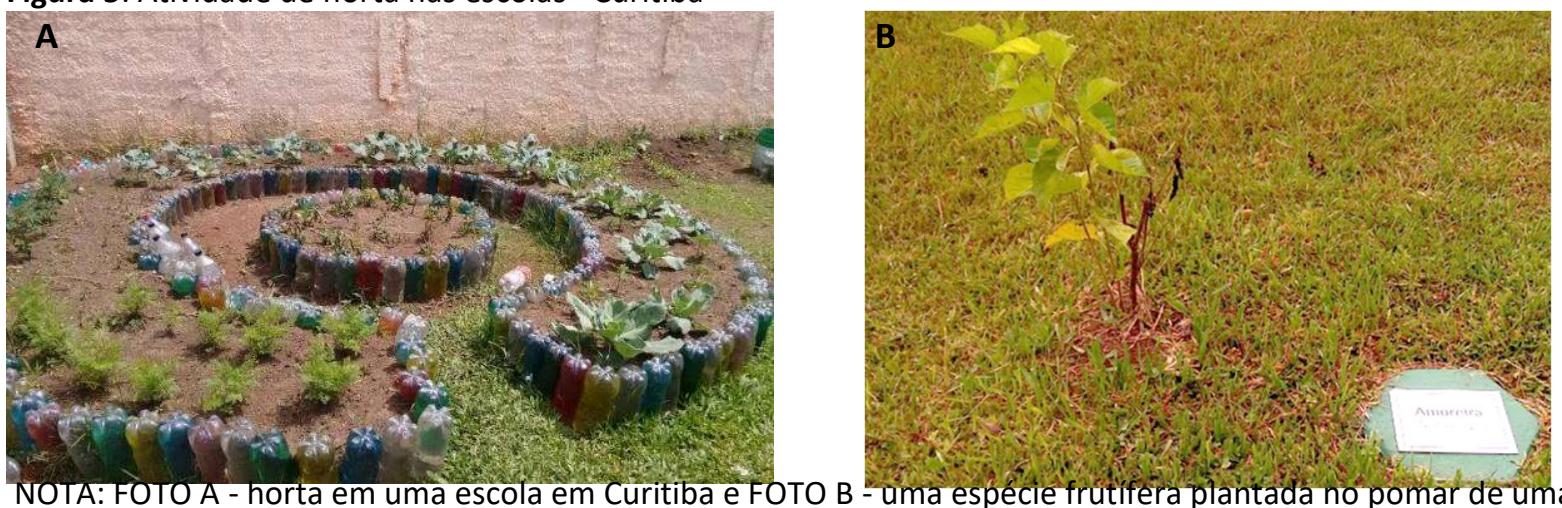
escola em Curitiba

Fonte: Elaborado pelas autoras, 2021.

Para Cribb (2010) projetos como horta, faz com que os estudantes auxiliem os professores na rega das hortaliças, incentiva o uso de produtos recicláveis utilizando garrafas pet como recipiente para mudas ou até mesmo para delimitar o canteiro e estimulam as crianças a consumirem o alimento que elas ajudaram a produzir. Essas atividades também 
auxiliam no contato dos estudantes com as plantas, aprendendo desde o preparo da terra até o seu plantio, além de acompanhar os estágios de desenvolvimento dos vegetais (MOURO; AUGUSTO, 2019).

Projetos que envolvam mais de um tema específico, possibilita que os estudantes pensem em soluções mais sustentáveis no seu dia a dia. Para Rezende e Bampi (2019), a escola é um espaço privilegiado para desenvolver novas condutas, concepções e valores ambientais, possibilitando aos estudantes uma postura sustentável.

\section{CONSIDERAÇÕES FINAIS}

Das 35 escolas municipais avaliadas em Curitiba, 23 apresentam atividades de educação ambiental que envolve projetos no ensino formal, dos quais não houve diferença estatística na forma que esses projetos são aplicados entre os tipos de ensino, embora apenas as com ensino integral tinham projetos em todas as escolas avaliadas, que provavelmente está atrelado as atividades do contraturno.

Dentre as formas que os projetos são desenvolvidos, a maior parte integrava o tema ao projeto político pedagógico da escola e a partir de questões socioambientais relacionadas aos conteúdos disciplinares, o que demostra que as atividades estão alinhadas a política escolar e estão de acordo com a política nacional de educação ambiental, com o compromisso de repassar os temas de forma transversal e interdisciplinar.

As atividades realizadas nas escolas são engajadas geralmente por um grupo de professores, seguido também pela participação de diversos agentes da comunidade escolar, ressaltando a importância da inclusão dos alunos no desenvolvimento dos projetos, para melhorar o interesse em relação aos temas aplicados, dos quais os mais abordados foram a água, o lixo e reciclagem e a saúde e nutrição.

\section{REFERÊNCIAS}

BRANDT, L. S. O papel do articulador pedagógico frente às tecnologias de informação e comunicação na EJA da rede municipal de Curitiba. Curitiba. Anais... Curitiba: XIII Congresso de educação, 2017. 
BRASIL. Lei n. 9.795, de 27 de abril de 1999. Diário Oficial da União. Dispõe sobre a educação ambiental, institui a Política Nacional de Educação AmbientalDisponível em: <http://www.mma.gov.br/port/conama/legiabre.cfm?codlegi=321>. Acesso em: 04 ago. 2019.

BRASIL. Parecer CNE/CP n.o 14/2012, 6 de junho de 2012a. Diretrizes Curriculares Nacionais para a Educação Ambiental. Diário Oficial da União. Disponível em: $<$ http://portal.mec.gov.br/index.php?option=com_content\&id=17631\&ltemid=866>. Acesso em: 04 ago. 2019.

CRIBB, S. Contribuições da educação ambiental e horta escolar na promoção de melhorias ao ensino, à saúde e ao ambiente. Revista Eletrônica do Mestrado Profissional em Ensino, Saúde e Ambiente, Rio Grande, v. 3, n. 1, p. 42 - 60, 2010.

CURITIBA. Diretrizes Curriculares para a Educação Municipal de Curitiba: Educação Especial e Inclusiva, Educação Integral, Educação de Jovens e Adultos. Curitiba: Secretaria Municipal Educação, 2006.

CURITIBA. Unidades Educacionais. 2017. Disponível em: <http://www.educacao.curitiba.pr.gov.br/>. Acesso em: 10 de abr. 2017.

CRUZ, S. Educação ambiental e o projeto político-pedagógico: em busca da sustentabilidade ambiental. Periódico Eletrônico Fórum Ambiental da Alta Paulista, v. 7, n. 6, p. 921 - 933, 2011.

FREITAS, N. T. A.; MARIN, F. A. D. G. Educação ambiental e água: concepções e práticas educativas em escolas municipais. Nuances: estudos sobre Educação, Presidente Prudente, v. 26, número especial 1, p. 234 - 253, 2015.

INSTITUTO NACIONAL DE ESTUDOS E PESQUISAS EDUCACIONAIS ANÍSIO TEIXEIRA - INEP. Sistema de Consulta a Matrícula do Censo Escolar. 2017. Disponível em: < http://portal.inep.gov.br/resultados-e-resumos>. Acesso em: 10 jun. 2017.

LAMOSA, A. C.; LOUREIRO, C. F. B. A educação ambiental e as políticas educacionais: um estudo nas escolas públicas de Teresópolis (RJ). Educação e Pesquisa, São Paulo, v. 37, n.2, p. 279 - 292, 2011.

LUCHESA, C. J.; CHAVES NETO, A. Cálculo do tamanho da amostra nas pesquisas em administração. Curitiba: Edição do autor, 2011.

MENDONÇA, P. R.; TRAJBER, R. $\mathbf{O}$ que fazem as escolas que dizem que fazem educação ambiental. ed. 6. Brasília: Secretaria de Educação Continuada, Alfabetização e Diversidade, 2007. 262 p.

MOURO, B. C.; AUGUSTO, T. G. S. Educação ambiental e a horta escolar: um diagnóstico de projetos desenvolvidos e das possibilidades de ação. Educação Ambiental em Ação, revista 
eletrônica, $\quad$ n. $2019 . \quad$ 66, Disponível

http://www.revistaea.org/artigo.php?idartigo=3494>. Acesso em: 10 jan. 2019.

NARCIZO, K. R. S. Uma análise sobre a importância de trabalhar educação ambiental nas escolas. Revista Eletrônica do Mestrado em Educação Ambiental, Rio Grande, v. 22, p. 86 94, 2009.

HIGUCHI, M. I. G.; ZATTONI, M.; BUENO, F. P. Educação Ambiental em contextos não escolares: definindo, problematizando e exemplificando. Pesquisa em Educação Ambiental, Rio Claro, v. 7, n. 2, p. 119-132, 2012.

PALMIERI, M. L. B.; CAVALARI, R. M. F. Objetivos de projetos de educação ambiental desenvolvidos em escolas brasileiras: um estudo de dissertações e teses (1988-2008). Revista Comunicações, Piracicaba, v. 20, p. 99 - 118, 2013.

PALMIERI, M. L. B.; CAVALARI, R. M. F. Limites e possibilidades dos projetos de educação ambiental desenvolvidos em escolas brasileiras: análise de dissertações e teses. Revista Eletrônica do Mestrado em Educação Ambiental, Rio Grande, v. 29, p. 1-17, 2012.

R CORE TEAM. 2016. R: A language and environment for statistical computing. R Foundation for Statistical Computing, Vienna, Austria. Disponível em: <https://www.R-project.org/>. Acesso em: 04 jun. 2017.

REIGOTA, M. O que é educação ambiental. São Paulo: Editora Brasiliense, 2017. 88p.

REIS, L. C. L.; SEMÊDO, L. T. D. A. S.; GOMES, R. C. Conscientização ambiental: da educação formal a não formal. Revista Fluminense de Extensão Universitária, Vassouras, v. 2, n. 1, p. 47 - 60, 2016.

REZENDE, F. S. S. L.; BAMPI, A. C. Práticas pedagógicas em educação ambiental na educação básica: dificuldades e potencialidades da inserção da temática nas escolas. Educação Ambiental em Ação, revista eletrônica, n. 67, 2019. Disponível em: < http://www.revistaea.org/artigo.php?idartigo=3597>. Acesso em: 10 jan. 2019.

SANTOS, T. M. M.; OLIVEIRA, J. L. S.; OLIVEIRA, H M.; SILVA, E. Recursos hídricos: problemas ambientais e a importância da educação e percepção ambiental. Educação Ambiental em Ação, revista eletrônica, n. 65, 2018. Disponível em: < http://www.revistaea.org/artigo.php?idartigo=3416>. Acesso em: 10 jan. 2019.

SARTORI, J. T. D. Estatísticas da educação particular do Paraná: educação básica e superior. 1.ed. Curitiba: Sinepe/PR, 2015. 104 p.

SIEGEL, S.; CASTELLAN JR, N. J. Estatística não-paramétrica para ciências do comportamento. Porto Alegre: Artmed Editora SA., ed. 2006.

SOUZA, D. A.; BONOTTO, D. M. B. Valores Éticos e Estéticos Relativos à Temática Ambiental e a Literatura Infantil. Pesquisa em Educação Ambiental, São Paulo, v. 14, n. 1, p. 132 